\title{
Lateral Excitation within the Olfactory Bulb
}

\author{
Jason M. Christie ${ }^{1,2}$ and Gary L. Westbrook ${ }^{1}$ \\ ${ }^{1}$ Vollum Institute and ${ }^{2}$ Neuroscience Graduate Program, Oregon Health and Science University, Portland, Oregon 97239
}

\begin{abstract}
Lateral inhibition is a common feature of cortical networks, serving such functions as contrast enhancement. In the olfactory bulb, inhibition is imbedded in the local connectivity at dendrodendritic synapses between mitral cells and interneurons. However, there is also evidence for excitatory interactions between mitral cells despite the lack of direct synaptic connections. This lateral excitation, although a less well recognized feature of the circuit, provides a potentially powerful mechanism to enhance coordinated activity. We examined lateral excitation in paired recordings between mitral cells projecting to the same glomerulus. Trains of action potentials in one mitral cell evoked autoexcitation in the stimulated cell and a prolonged depolarization in the second cell. This lateral excitation was absent in connexin $36^{-I-}$ mice, which lack mitral-mitral cell gap junctions. However, spillover of dendritically released glutamate contributed to lateral excitation during concerted mitral cell excitation or by single-cell activity if glutamate uptake was blocked. Our results suggest that electrical coupling and spillover create a lateral excitatory network within the glomerulus, thus markedly amplifying the sensitivity of each glomerulus to incoming sensory input.
\end{abstract}

Key words: glutamate; spillover; connexin36; mitral cell; NMDA receptor; AMPA receptor

\section{Introduction}

Within neural networks, the activation of one neuron can lead to excitation of neighboring neurons by means other than conventional point-to-point synaptic transmission. This lateral excitation may include spillover of fast-acting transmitters, volume transmission of monoamines or neuromodulators, electrical coupling via gap junctions, or even direct electrical field effects within bundles of axons (Fuxe and Agnati, 1991; Jefferys, 1995; Kullmann, 2000; Bennett and Zukin, 2004). Although this form of activity can degrade synaptic specificity, it can also coordinate or amplify activity within groups of cells (Engert and Bonhoeffer, 1997; Scanziani, 2000). The importance of these mechanisms for a specific circuit varies. In the olfactory bulb, the mapping of olfactory receptor neurons (ORNs) onto specific glomeruli (Mombaerts et al., 1996) suggests that the network may be specialized to coordinate activity within glomerular units. In contrast to the lateral inhibition mediated by dendrodendritic synapses (Jahr and Nicoll, 1982; Isaacson and Strowbridge, 1998; Schoppa et al., 1998), the mechanisms of lateral excitation are not well understood.

Sensory processing in the olfactory bulb involves both chemical and electrical components. Mitral cells, the principal neurons of the olfactory bulb, release glutamate from primary and secondary dendrites at dendrodendritic synapses (Shepherd and Greer, 1998). Glutamate released from mitral cells not only excites postsynaptic targets, but also causes autoexcitation medi-

Received Nov. 8, 2005; revised Jan. 16, 2006; accepted Jan. 17, 2006.

This work was supported by the National Institutes of Health (NS26494 to G.L.W.; 1F31-DC051224 to J.M.C.) and the Max Planck Society. We thank members of the Westbrook laboratory for their helpful discussions. In addition, we thank Aesoon Benson for her assistance. The $\mathrm{C}_{3} 6^{-1-}$ mice were provided by Dr. Hannah Monyer.

Correspondence should be addressed to Jason M. Christie, Vollum Institute, Oregon Health and Science University, 3181 Southwest Sam Jackson Park Road, Portland, OR 97239. E-mail: christij@ohsu.edu.

DOI:10.1523/JNEUROSCI.4791-05.2006

Copyright $\odot 2006$ Society for Neuroscience $\quad$ 0270-6474/06/262269-09\$15.00/0 ated by NMDA and AMPA autoreceptors along the "presynaptic" dendrite (Nicoll and Jahr, 1982; Aroniadou-Anderjaska et al., 1999; Isaacson, 1999; Salin et al., 2001; Schoppa and Westbrook, 2001). Excitation between mitral cells, mediated by NMDA and AMPA receptors (Isaacson, 1999; Schoppa and Westbrook, 2001; Urban and Sakmann, 2002), is thought to occur between mitral cells sharing the same dendritic glomerular projection (Schoppa and Westbrook, 2001; Urban and Sakmann 2002). Because mitral cells lack direct synaptic contact with other mitral cells (Price and Powell, 1970; Pinching and Powell, 1971), excitation of surrounding cells and dendrites has been attributed to glutamate spillover. At first glance, this is not surprising because glomeruli are highly compartmentalized (Chao et al., 1997; Kasowski et al., 1999). Thus, glial ensheathed bundles of primary dendrites could provide a chemical compartment for glutamate pooling (Carlson et al., 2000; Schoppa and Westbrook, 2002). However, gap junctions mediated by connexin36 (Cx36) also influence the electrical activity of mitral cells within a glomerulus (Schoppa and Westbrook, 2002; Christie et al., 2005). In fact, the role of gap junctions in lateral excitation has been demonstrated nicely in the escape reflex of the crayfish (Herberholz et al., 2002; Antonsen et al., 2005).

Using paired mitral cell recording, we examined the mechanism underlying lateral excitation in olfactory bulb slices from wild-type (WT) and Cx36 ${ }^{-1-}$ mice. Electrical coupling between mitral cells played the predominant role conveying excitation between pairs of mitral cells. We were unable to detect intraglomerular spillover evoked by single mitral cell activity. In the absence of mitral-mitral cell gap junctions, spillover only occurred when glutamate uptake was blocked or during simultaneous activation of many mitral cells. Our results indicate that the electrical coupling and spillover enhances excitability within mitral cell circuits and serves to boost the gain of sensory signals. 


\section{Materials and Methods}

Horizontal slices of the main olfactory bulb $(250-300 \mu \mathrm{m})$ were prepared from WT and Cx36 ${ }^{-1-}$ mice [C57BL/6; postnatal day 14 (P14) to P21] (Hormuzdi et al., 2001). Mice, anesthetized with halothane, were decapitated and olfactory bulbs were removed. Slices were cut in ice-cold oxygenated solution containing the following (in $\mathrm{mm}$ ): $83 \mathrm{NaCl}, 26.2$ $\mathrm{NaCHO}_{3}, 2.5 \mathrm{KCl}, 1 \mathrm{NaH}_{2} \mathrm{PO}_{4}, 3.3 \mathrm{MgCl}_{2}, 0.5 \mathrm{CaCl}_{2}, 22$ glucose, and 72 sucrose, $\mathrm{pH}$ 7.3. Slices were transferred to a warmed bath $\left(35^{\circ} \mathrm{C}\right)$ for 30 min then incubated at room temperature until use.

Whole-cell recordings were obtained under visual control using differential interference contrast (DIC) optics (Carl Zeiss, Oberkochen, Germany) in a base solution $\left(32-35^{\circ} \mathrm{C}\right.$ ) containing (in $\mathrm{mm}$ ): $119 \mathrm{NaCl}$, $26.2 \mathrm{NaCHO}_{3}, 2.5 \mathrm{KCl}, 1 \mathrm{NaH}_{2} \mathrm{PO}_{4}, 1.3 \mathrm{MgCl}_{2}, 2.5 \mathrm{CaCl}_{2}$, and 22 glucose, $\mathrm{pH}$ 7.3. For some voltage-clamp experiments, $\mathrm{MgCl}_{2}$ was omitted and TTX $(0.5-1 \mu \mathrm{m})$ was added. All experiments were performed in the presence of the $\mathrm{GABA}_{\mathrm{A}}$ antagonist SR 95531 hydrobromide 6-lmino-3(4-methoxyphenyl)-1(6H)-pyridazinebutanoic acid hydrobromide; $2-5$ $\mu \mathrm{M}]$. Patch pipettes $(4-6 \mathrm{M} \Omega)$ in current-clamp recordings contained (in mM): $125 \mathrm{~K}$-gluconate, $2 \mathrm{MgCl}_{2}, 0.025 \mathrm{CaCl}_{2}, 1$ EGTA, $2 \mathrm{NaATP}, 0.5$ NaGTP, and 10 HEPES, pH 7.3. For voltage-clamp recording, pipettes contained (in mM) 125 Cs-gluconate, $2 \mathrm{MgCl}_{2}, 0.025 \mathrm{CaCl}_{2}, 1$ EGTA, 2 NaATP, 0.5 NaGTP, 10 HEPES, 10 4-aminopyridine, and 15 tetraethylammonium chloride, $\mathrm{pH} 7.3$.

Electrophysiological recordings were made with Axopatch 200A and 200B amplifiers (Molecular Devices, Union City, CA). Analog signals were filtered at $2 \mathrm{kHz}$ with the eight-pole Bessel filters of the amplifiers and digitized at $10 \mathrm{kHz}$. In some cases, a 10-point sliding boxcar filter was applied to small amplitude currents (see Figs. 4, 5). Data were acquired and analyzed using Axograph 4.6 (Molecular Devices). In current-clamp experiments, mitral cells were often held at hyperpolarized potentials compared with rest (approximately $-60 \mathrm{mV}$ ) to prevent random spiking. Unless indicated otherwise, cells were held at $-60 \mathrm{mV}$ during voltage-clamp experiments.

Some mitral cells were excited via antidromic stimulation of the lateral olfactory tract, the tight bundle of mitral cell axons exiting the olfactory bulb. The lateral olfactory tract (LOT) was easily identified with DIC optics. The LOT was preserved in slices by positioning the dissected olfactory bulb and proximal portion of cortex $(\approx 5 \mathrm{~mm})$ in horizontal register with the basal part of the brain (Aroniadou-Anderjaska et al., 1999). For stimulation, a bipolar electrode was positioned on the surface of the LOT, $75-150 \mu \mathrm{m}$ from the test mitral cell. Brief stimulating pulses $(100 \mu \mathrm{s}, 10-100 \mathrm{~V}, 0.05 \mathrm{~Hz})$ were triggered by a stimulation isolation unit (Digitimer, Hertfordshire, UK). For olfactory nerve stimulation, a bipolar electrode was placed on the surface of visually identified bundles of afferents near the presumed glomerulus to which the test mitral cell(s) projected. Brief pulses $(100 \mu \mathrm{s}, 10-100 \mathrm{~V}, 0.05 \mathrm{~Hz})$ were used to evoke mitral cell responses.

Because the full extent of primary dendrites and their glomerular tufts could not be determined by DIC optics, we used several methods to determine the glomerular projection of mitral cells. Cells projecting to the same glomerulus could be confirmed in WT mice by the presence of direct electrical coupling (Schoppa and Westbrook, 2002; Christie et al., 2005). Mitral cells projecting to the same glomerulus in $\mathrm{C} \times 36^{-/-}$mice were indicated by highly correlated depolarizations induced by DL-threo$\beta$-venzyloxyaspartic acid (TBOA) (Christie et al., 2005). Some mitral cell pairs (WT and $\mathrm{C} \times 36^{-\prime-}$ ) were filled with fluorescent indicators, allowing the direct visual confirmation of dendritic glomerular projection (see below).

The coupling coefficient (CC) of mitral cell pairs in WT mice was determined as described previously (Schoppa and Westbrook, 2002; Christie et al., 2005). Briefly, hyperpolarizing current injections (100$500 \mathrm{pA}, 500 \mathrm{~ms}$ ) elicited large voltage deflections $(15-30 \mathrm{mV})$ in the stimulated cell. If the adjacent test cell projected to the same glomerulus, small voltage deflections were also recorded reflecting electrical coupling. CC equals the size of the voltage deflection in the test cell divided by the deflection in the stimulated cell.

For morphological characterization of mitral cell pairs, we filled cells with biocytin $(0.1 \%)$ or Lucifer yellow $\left(0.1 \%\right.$; $\mathrm{KCl}$ for $\mathrm{K}^{+}$patch solu- tions; $\mathrm{LiCl}$ for $\mathrm{Cs}^{+}$patch solutions). Slices were fixed in $4 \%$ formaldehyde/PBS (72 mm NaH $\mathrm{PO}_{4}$ and $28 \mathrm{~mm} \mathrm{Na}_{2} \mathrm{HPO}_{4}$, pH 7.2) overnight. Slices were then permeabilized (0.4\% Triton X-100) and labeled in PBS. For biocytin fills, cyanine-5-conjugated strepavidin (1:2000; Jackson ImmunoResearch, West Grove, PA) was added $\left(12 \mathrm{~h}\right.$ at $\left.4^{\circ} \mathrm{C}\right)$ in PBS/ Triton $\mathrm{X}-100$. Slices were washed in Triton-free PBS (three times; $10 \mathrm{~min}$ ) and then blocked with 5\% goat serum and $0.4 \%$ Triton X-100 (30 min). For Lucifer yellow fills, anti-Lucifer yellow IgG (1:1000; Invitrogen, San Diego, CA) was added $\left(12 \mathrm{~h}\right.$ at $\left.4^{\circ} \mathrm{C}\right)$. Slices were washed in PBS (three times; $10 \mathrm{~min}$ ) and labeled with a secondary antibody (goat anti-rabbit Alexa 488; 1:500; Invitrogen). After washing in PBS (three times; $10 \mathrm{~min}$ ), propidium iodide (1:2000; Invitrogen) was used as a nuclear counter stain. Slices were mounted on slides with ProLong Antifade (Invitrogen) and imaged on a confocal microscope (Olympus, Melville, NY) equipped with a $20 \times$ objective. For measurement of putative contact points (see Fig. 3), investigators (blinded to the genotype) analyzed $z$-stack images of glomerular tufts $(100 \times$ magnification $)$. A contact point was defined as dendrite crossings or areas where the labels were contiguous.

For all experiments, Student's $t$ tests (two-tailed) were used for pair comparisons, and ANOVA was used for multiple comparisons, as appropriate. Significance was set at 0.05 for $t$ tests. Results are reported as mean \pm SEM.

\section{Results}

\section{Lateral excitation of adjacent mitral cells}

We used short trains of action potentials $(120-360 \mathrm{~Hz})$ elicited by current injection (500-1750 pA, $50 \mathrm{~ms}$ ) to evoke glutamate release from mitral cells. In the stimulated cell, a depolarizing afterpotential followed the spike train (Fig. $1 A_{1}$, top, $\mathrm{M}_{\mathrm{A}}$ ) and was sensitive to glutamate receptor antagonists, consistent with glutamatergic autoexcitation (Nicoll and Jahr, 1982; AroniadouAnderjaska et al., 1999; Isaacson, 1999; Friedman and Strowbridge, 2000; Salin et al., 2001; Schoppa and Westbrook, 2001). The autoexcitatory potential was difficult to quantify, because the current injection also evoked a prominent afterhyperpolarization. In paired recording of mitral cells projecting to the same glomerulus, the action potential train in the stimulated cell also depolarized the unstimulated cell (Fig. $1 A_{1}$, bottom, $\mathrm{M}_{\mathrm{B}}$ ). This lateral excitation was a few millivolts in amplitude (integral, $0.314 \pm 0.047 \mathrm{mV} \cdot \mathrm{s})$ and lasted for hundreds of milliseconds [half width $\left(w_{1 / 2}\right), 99.8 \pm 8.4 \mathrm{~ms} ; n=16$ ]. Block of lateral excitation with D,L-AP-5 or 2,3-dihydroxy-6-nitro-7-sulfonylbenzo[f] quinoxaline (NBQX) revealed both NMDA and AMPA receptor-mediated components (Fig. $\left.1 A_{1}, A_{2}\right)$. AP-5 $(100 \mu \mathrm{M})$ reduced lateral excitation $(62.4 \pm 6.1 \%$ of control; $n=8)$, whereas NBQX $(20 \mu \mathrm{M})$ nearly eliminated the potential $(22.4 \pm$ $6.5 \%$ of control in the presence of AP-5, $n=4 ; 30.7 \pm 8.0 \%$ of control in the absence of AP-5, $n=9 ; p=0.53$ ) (Fig. $1 A_{1}$ ). Thus, the NMDA receptor component required the coactivation of AMPA receptors. Because mitral cells that project to the same glomerulus are electrically coupled (Schoppa and Westbrook, 2002; Christie et al., 2005), the small potential that persisted in the presence of NBQX most likely reflects electrical coupling of the depolarizing current injection from the stimulated cell. Consistent with this possibility, depolarization of the stimulating cell in NBQX, evoked from a hyperpolarized potential to prevent action potential firing, did not alter the size of the response in the test cell (action potential train, $0.074 \pm 0.18 \mathrm{mV} \cdot \mathrm{s}$; subthreshold stimulation, $0.081 \pm 0.018 \mathrm{mV} \cdot \mathrm{s} ; n=5 ; p=0.78$ ).

Paired recordings from mitral cells that projected to different glomeruli failed to generate depolarizations in test cells (integral, $0.010 \pm 0.005 \mathrm{mV} \cdot \mathrm{s} ; n=10$ ) (Fig. $1 B$ ), indicating that lateral excitation originated in the glomerulus. Responses between cells within a glomerulus have been attributed to glutamate spillover between closely apposed dendrites (Schoppa and Westbrook, 
$\mathrm{A}_{1}$ wT Same Glom.
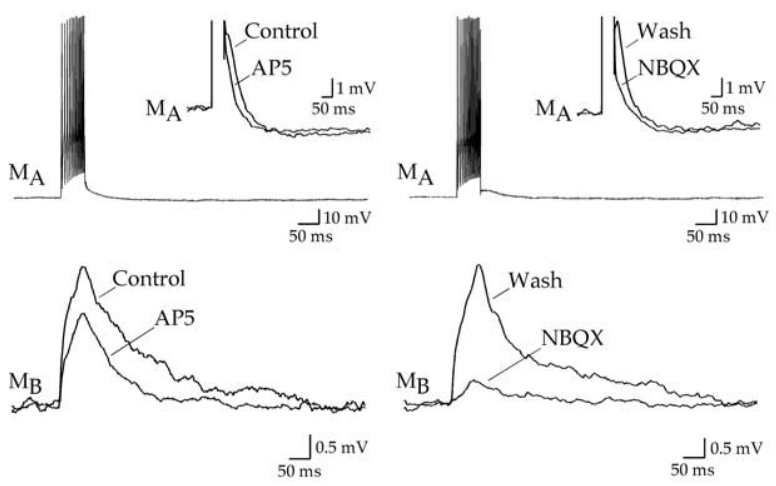

$\mathrm{A}_{2}$
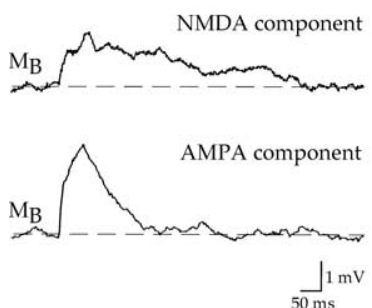

$\mathrm{A}_{3}$

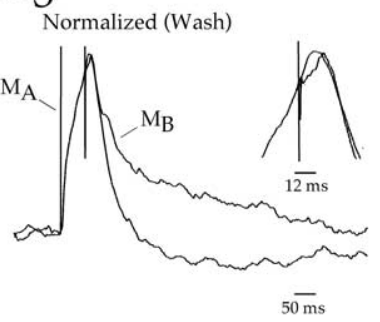

B wT Diff. Glom.
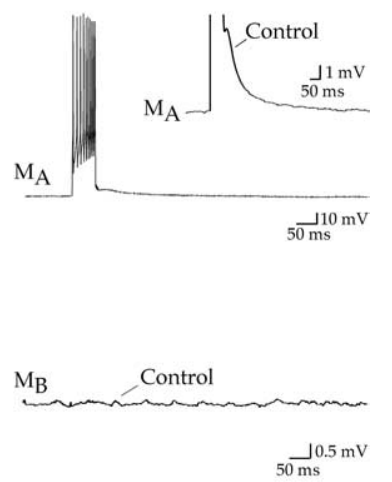

C

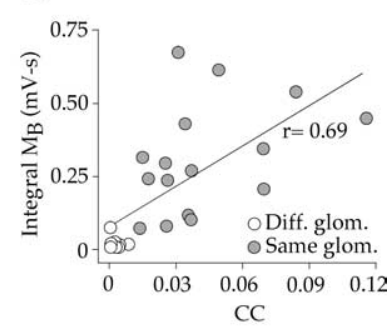

Figure 1. Intraglomerular lateral excitation in WT mice. $\boldsymbol{A}_{\boldsymbol{1}}$, In paired recording of mitral cells that projected to the same glomerulus, a train of action potentials evoked an autoexcitatory potential in the stimulated cell $\left(M_{A}\right)$ (inset, enlarged average trace) and a depolarization (lateral excitation) in the test cell $\left(M_{B}\right)$. Lateral excitation was partly reduced by AP-5 (bottom left). After washout of AP-5, the response was nearly abolished by NBQX (bottom right). The residual depolarization in the test cell reflects direct electrical coupling of the depolarization in $\mathrm{M}_{\mathrm{A}} . \boldsymbol{A}_{2}$, Subtraction revealed both a prolonged NMDA receptor-mediated component and a brief AMPA receptor-mediated component. $\boldsymbol{A}_{3}$, Normalized autoexcitatory and lateral excitatory potentials showed a similar time to peak (inset, expanded view). $\boldsymbol{B}$, An action potential train in a paired recording from mitral cells projecting to different glomeruli failed to evoke lateral excitation in the test cell $\left(M_{B}\right)$. C, Pooled data for all WT cell pairs showed a correlation between the electrical $C\left(\right.$ and lateral excitation, as measured as the integral of the depolarization (integral $\left.\mathrm{M}_{B}\right)(p=0.05)$. Diff., Different; Glom., glomerulus; Wash, washout.

2001; Urban and Sakmann, 2002). Alternatively, electrical coupling of the autoexcitatory potential (Schoppa and Westbrook, 2002) may also contribute. Spillover should entail some delay attributable to diffusion of glutamate. However, lateral excitation actually peaked slightly ahead of the peak of the autoexcitatory potential in the stimulated cell $(9.3 \pm 6.2 \mathrm{~ms} ; n=8)\left(\right.$ Fig. $\left.1 A_{3}\right)$. The size of lateral excitation also correlated with the coupling coefficient (Fig. 1C), suggesting that there was a relationship between electrical coupling and the depolarization in the test cell.

To examine the role of gap junctions in lateral excitation, we used $\mathrm{Cx} 36^{-1-}$ mice that lack electrical coupling between mitral cells within a glomerulus (Christie et al., 2005). In Cx36 ${ }^{-/-}$mice, action potential trains in a mitral cell evoked an autoexcitatory potential in the stimulated cell, similar to WT mice. However, the stimulation failed to evoke lateral excitation even in mitral cells that projected to the same glomerulus $(0.009 \pm 0.004 \mathrm{mV} \cdot \mathrm{s} ; n=$ 8) (Fig. $2 A$ ). Thus, action potential trains are not sufficient to generate spillover responses between mitral cell pairs in the absence of gap junctions.

\section{Unmasking lateral excitation in $\mathrm{Cx} 36^{-/-}$mice}

Block of glutamate transporters can enhance spillover in many neuronal circuits (Scanziani et al., 1997; Diamond, 2001; ArnthJensen et al., 2002; Clark and Cull-Candy, 2002). Therefore, we tested the effect of the specific glutamate transporter blocker TBOA in $\mathrm{Cx} 36^{-1-}$ mice. For mitral cells projecting to the same glomerulus, action potential trains in the presence of TBOA (50 $\mu \mathrm{M})$ evoked a depolarization in seven of eight test cells $(0.362 \pm 0.108 \mathrm{mV} \cdot \mathrm{s} ; n=7)$ (Fig. $2 A, C$ ). In addition, the peak of the depolarization in the test cell was now delayed compared with the peak of the autoexcitatory potential $(56.6 \pm 7.9 \mathrm{~ms} ; n=5)$ (Fig. $2 B$, top), as might be expected for intraglomerular diffusion of glutamate. TBOA did not reveal lateral excitation in mitral cell pairs projecting to different glomeruli $(-0.015 \pm 0.025 \mathrm{mV} \cdot \mathrm{s} ; n=5)$ (Fig. $2 C)$, consistent with the idea that glomeruli function as separate units (Schoppa and Urban, 2003).

Glutamate spillover responses are typically mediated by NMDA receptors, presumably because of their high affinity for glutamate and/or their location (Barbour and Häusser, 1997). However, NBQX (20 $\mu \mathrm{M})$, but not AP-5 (100 $\mu \mathrm{M})$, blocked lateral excitation in $\mathrm{Cx} 36^{-1-}$ mice (Fig. $2 B$, bottom, $D$ ). This differed from WT mice, in which the lateral excitation was partially blocked by AP-5. These results suggest that, in the absence of gap junctions, spillover occurs when uptake is diminished or overwhelmed.

To exclude the possibility that the lack of lateral excitation in $\mathrm{Cx} 36^{-/-}$was caused by changes in the apposition of dendrites in the glomerulus, we compared the morphology of mitral cell dendrites in WT and $\mathrm{Cx} 36^{-1-}$ mice. We labeled pairs of mitral cells projecting to the same glomerulus with either biocytin or Lucifer yellow. As reported previously (Christie et al., 2005), mitral cells from both WT and $\mathrm{Cx} 36^{-1-}$ mice had several secondary dendrites as well as single primary dendrites ending in glomerular tufts (Fig. $3 \mathrm{~A}, \mathrm{C}$ ). Extensive overlapping of dendritic tufts was apparent in both lines (Fig. $3 B, D$ ), and analysis of confocal $z$-stacks (see Materials and Methods) did not reveal differences in the number of putative contacts (Fig. 3E). The number of putative contacts correlated with the coupling coefficient for mitral cell pairs in WT mice (Fig. $3 F$ ), suggesting that the analysis of the images provided a reasonable estimate of the interactions between dendrites.

\section{NMDA receptor-mediated spillover}

Our results thus far indicate that lateral excitation of mitral cells only occurs between mitral cells projecting to the same glomerulus and is mediated in part by AMPA receptors. This contrasts with a spillover current mediated by NMDA receptors, as reported by Isaacson (1999). In that study, conditions favoring NMDA receptor activation evoked NMDA receptor-mediated currents in approximately one-half of nearby mitral cells. Although the glomerular targets of these cells were not determined, the frequency of such responses was much higher than one expects for finding cell pairs at random that project to the same glomerulus ( $\sim 10 \%$ in our experiments). Thus, we examined lateral excitation under the conditions used by Isaacson (1999). Cells were voltage clamped at $-60 \mathrm{mV}$ in $\mathrm{Mg}^{+2}$-free solution containing TTX $(1 \mu \mathrm{m})$. Voltage steps $(+10 \mathrm{mV}, 35 \mathrm{~ms})$ were used to excite mitral cells and evoke glutamate release. 
A $\mathrm{C} \times 36^{--}$Same Glom.

B
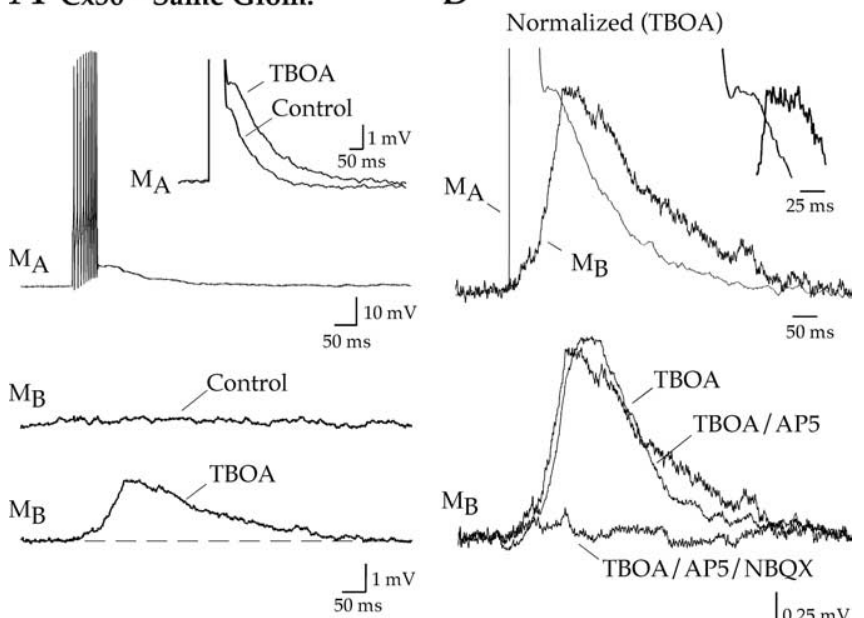

$\frac{1 \mathrm{mV}}{50 \mathrm{~ms}}$

C

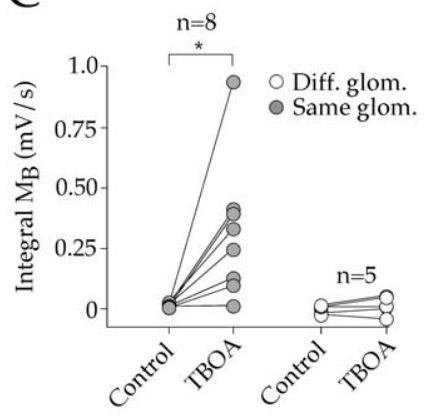

A

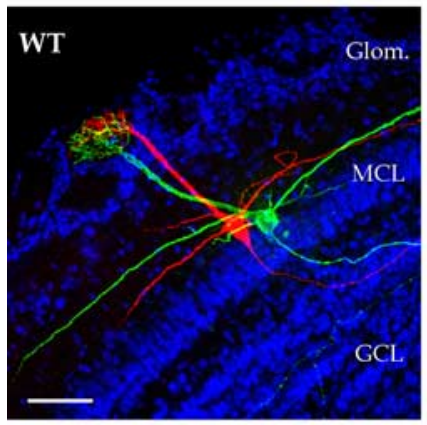

B

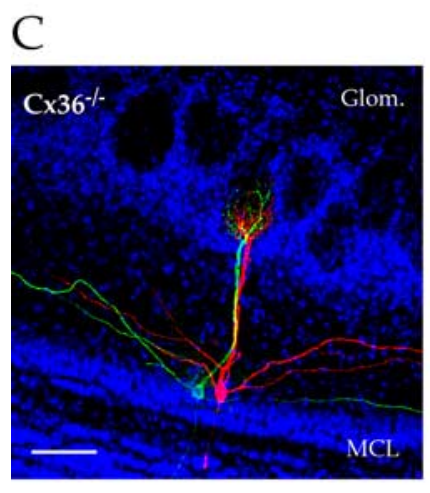

D

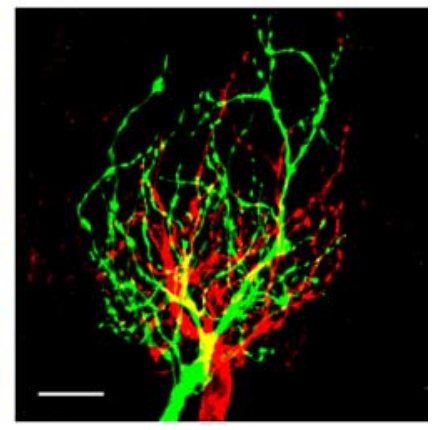

E

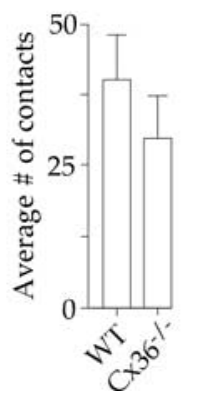

F

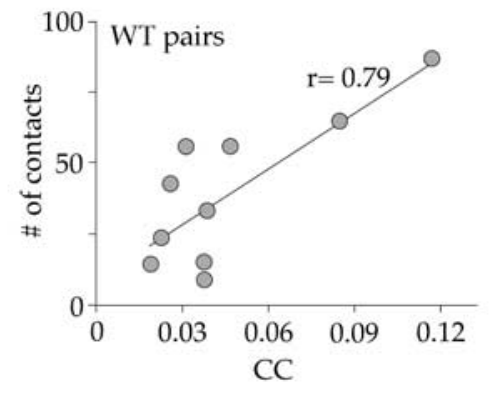

Figure 2. Intraglomerular lateral excitation in $\mathrm{C}_{3} 36^{-1-}$ mice. $\boldsymbol{A}_{1}, \ln \mathrm{C} \times 36^{-1-}$ mice, we recorded from pairs of mitral cells that projected to the same glomerulus. A train of action potentials evoked an autoexcitatory potential in the stimulated cell $\left(M_{A}\right)$. However, lateral excitation was absent in the test mitral cell $\left(\mathrm{M}_{B}\right)$. The glutamate transporter blocker TBOA (50 $\mu \mathrm{M}$ ) enhanced the autoexcitatory potential in the stimulated cell (inset) and revealed spillovermediated lateral excitation in the test cell. $\boldsymbol{B}$, Top, The lateral excitatory potential in TBOA peaked after the autoexcitatory potential; inset, expanded view. Bottom, NBQX, but not AP-5, blocked lateral excitation. C, TBOA-induced spillover only occurred between mitral cells that projected to the same glomerulus. $\boldsymbol{D}$, Pharmacological summary of lateral excitation. The electrically coupled potential in WT pairs was subtracted to reveal the antagonist sensitivity as shown in the AP- 5 (corr.) and NBQX (corr.) bars. Error bars represent SEM. ${ }^{*} p \leq 0.05$, statistical significance. Glom., Glomerulus; Diff., different; corrected; NA, not applicable.

As expected, direct mitral cell depolarization in WT mice elicited autoexcitatory currents that were sensitive to AP-5 (100 $\mu \mathrm{M})$ (Fig. $4 A_{1}$, top) (Isaacson, 1999; Friedman and Strowbridge, 2000). Lateral excitatory currents were also elicited in all cell pairs projecting to the same glomerulus $(n=11)$ (Fig. $4 A_{1}$, middle). Currents evoked between cells projecting to the same glomerulus were substantially larger $(79.3 \pm 23.6 \mathrm{pA} ; n=11)$ than those reported previously for random cell pairs by Isaacson (1999) (approximate range, $0-10 \mathrm{pA}$ ). Lateral excitation under these conditions was strongly inhibited by AP-5 (17.7 $\pm 2.4 \%$ of control; $n=9$ ). However, changes in the holding potential of test cells, and thereby the electrochemical gradient for NMDA receptor channels, had no effect on amplitude of the lateral excitatory current (Fig. $4 A_{1}$, bottom, $A_{2}$ ). This voltage independence suggests that the response in the test cell may involve electrical coupling. As for lateral excitation evoked by action potential trains, the size of lateral excitation evoked under these conditions was

Figure 3. Mitral cell dendritic morphology is similar in WT and $\mathrm{C}_{3} 36^{-1-}$ mice. $A$, C, Pairs of mitral cells were filled with biocytin (red) and Lucifer yellow (green) in a WT $(\boldsymbol{A})$ and a $\left(\times 36^{-1-}\right.$ (C) mouse. Propidium iodide was used to counter stain the cell body layers (blue). There were no apparent differences in mitral cell morphology. B, D, High-magnification (100× objective), confocal $z$-stack images of mitral cell dendritic tufts from $\boldsymbol{A}$ and $\boldsymbol{C}$. Both pairs had highly intercalated processes and extensive areas of overlap (yellow). Scale bars: $40,7,50$, and $7 \mu \mathrm{m}$ in $\boldsymbol{A}-\boldsymbol{D}$, respectively. $\boldsymbol{E}$, The number of putative contacts, defined by close membrane apposition or direct overlap, was not significantly different in WT and knock-out mice. Error bars represent SEM. $\boldsymbol{F}$, The number of putative contacts was correlated with the $\mathrm{C}(\mathrm{recorded}$ for each WT cell pair ( $p=0.007)$. Glom., Glomeruli; MCL, mitral cell layer; GCL, granule cell layer.

also tightly correlated with the coupling coefficient $(r=0.93 ; p<$ $0.001 ; n=16$ ).

In $\mathrm{C} \times 36^{-1-}$ mice, direct mitral cell depolarization elicited NMDA receptor-mediated autoexcitatory currents (Fig. $4 B$, top) that were slightly smaller than in WT mice (Fig. 4C, left). However, lateral excitation in $\mathrm{C} \times 36^{-1-}$ mice was virtually absent in mitral cell pairs projecting to the same glomerulus $(n=7)$ (Fig. $4 B, C)$. There was no detectable lateral excitatory current in four cells, whereas three other cells had extremely small currents $(3.8 \pm 1.2 \mathrm{pA} ; n=3)$, as shown in Figure $4 B$ (bottom and inset). These results indicate that electrical coupling dominates lateral excitation within the glomerulus and may obscure small spillover responses. There are reasons to consider sites where spillover 

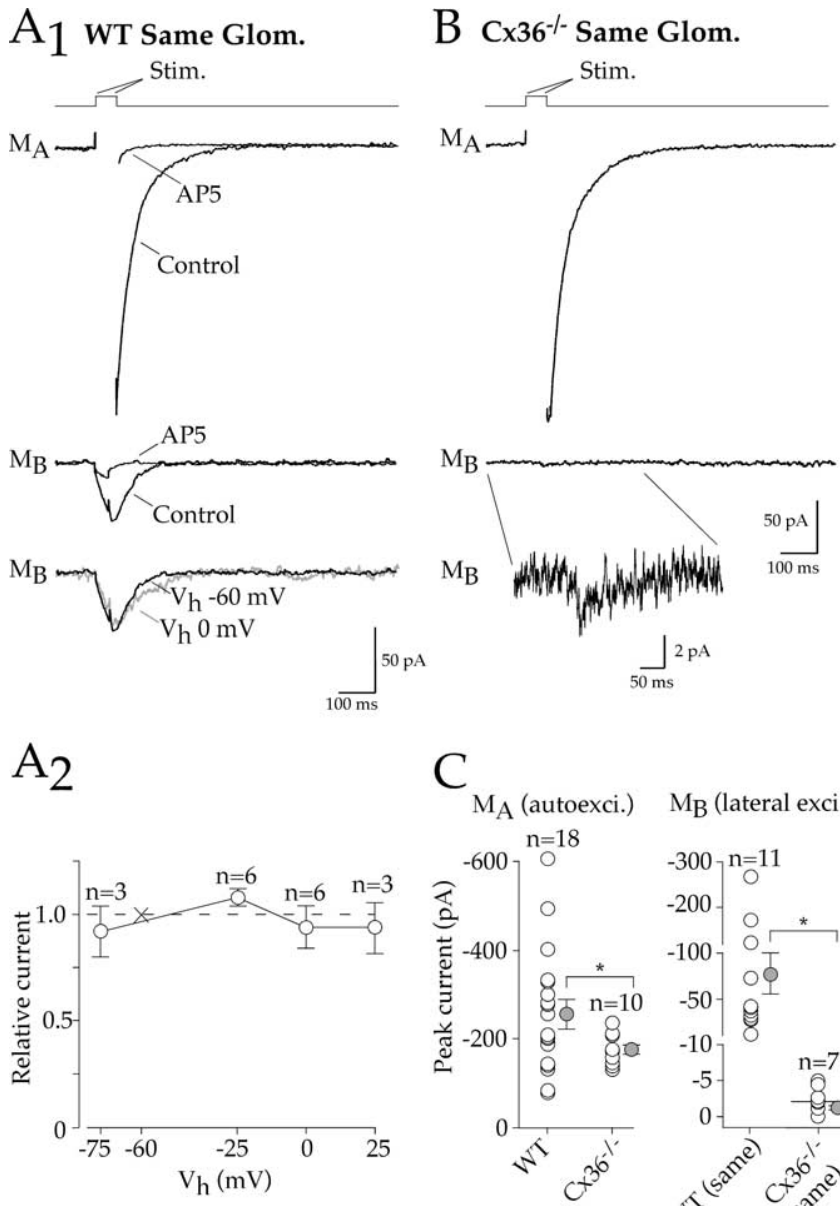

$\mathrm{M}_{\mathrm{B}}$ (lateral exci.)

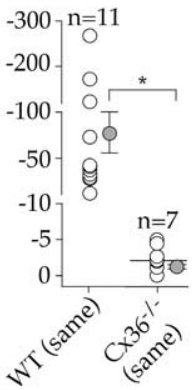

Figure 4. Lateral excitation evoked by step depolarizations under voltage clamp. $\boldsymbol{A}_{1}$, In a paired mitral cell recording $\left(0 \mathrm{Mg}^{+2}\right.$ and $1 \mu \mathrm{M}$ TTX), a brief voltage step (stimulation artifact removed) elicited an autoexcitatory current in the stimulated cell $\left(M_{A}\right)$ as well as a lateral excitatory current in a test mitral cell projecting to the same glomerulus $\left(M_{B}\right)$. Both the autoexcitatory and lateral excitatory currents were blocked by AP-5. Bottom, The amplitude of lateral excitation was the same at holding potentials $\left(V_{\mathrm{h}}\right)$ of -60 or $0 \mathrm{mV}$ in the test mitral cell. $A_{2}$, The current-voltage relationship of the lateral excitatory current was insensitive to $V_{h}$. Lateral excitatory currents measured at different holding potentials were normalized within each cell to the current at $-60 \mathrm{mV}$. B, Although a robust autoexcitatory current was generated in a $\mathrm{C} 36^{-1-}$ mitral cell, lateral excitation in the test cell was extremely small; inset, expanded trace. $\boldsymbol{C}$, Left, Summary graph shows that autoexcitatory currents were evoked in both WT and $\mathrm{C} \times 36^{-1-}$ mitral cells. Right, However, lateral excitation evoked between mitral cells projecting to the same glomerulus in WT mice was much larger than in $\mathrm{C}_{3} 36^{-1-}$ mice. Note scaling on $y$-axis. Error bars represent SEM. * $p \leq 0.05$, statistical significance. Glom., Glomerulus; Stim., stimulation; autoexci., autoexcitatory; exci., excitatory.

might occur other than the glomerulus. For example, glutamate release occurs at dendrodendritic synapses along secondary dendrites (Shepherd and Greer, 1998). As illustrated for a cell pair projecting to different glomeruli (Fig. $5 A_{1}$ ), secondary dendrites can be closely apposed. Thus, we also looked for evidence of spillover between pairs of mitral cells projecting to different glomeruli in WT mice. In four of eight cell pairs, small-amplitude $(4.0 \pm 0.9 \mathrm{pA} ; n=4)$ lateral excitatory currents were recorded in test mitral cells (Fig. $5 A_{2}, A_{3}$ ).

Block of glutamate uptake with TBOA $(50 \mu \mathrm{M})$ increased current amplitudes and unmasked currents in $\mathrm{Cx} 36^{-1-}$ pairs projecting to the same glomerulus and in WT pairs projecting to different glomeruli (Fig. $5 A_{2}, A_{3}, B_{1}, B_{2}, C$ ). These TBOA-enhanced currents were similar in amplitude $(8.7 \pm 1.9 \mathrm{pA} ; n=7)$ to the NMDA receptor-mediated spillover currents reported by Isaac- son (1999) and were also blocked by AP-5 (Fig. $5 A_{3}, B_{2}, C$ ). Thus, conditions favoring NMDA receptor activation can lead to small currents caused by spillover, most likely from secondary dendrites in the external plexiform layer. Using the voltage-step protocol, we did not detect an AMPA component in $\mathrm{Cx} 36^{-/-}$pairs, perhaps because space clamp was insufficient to depolarize distal dendritic compartments.

\section{Glutamate spillover evoked by LOT stimulation}

In the absence of electrical coupling, activation of single mitral cells produced little or no lateral excitation unless glutamate transporters were blocked with TBOA. However, mitral cells often respond to stimuli as synchronous ensembles (Carlson et al., 2000; Schoppa and Westbrook, 2001; Christie et al., 2005). This raises the possibility that glutamate release from multiple cells could overcome transporter buffering of glutamate and excite neighboring cells as reported in hippocampus (Arnth-Jensen et al., 2002). To test this possibility, we simultaneously activated a population of mitral cells by stimulating the LOT with a bipolar electrode (100 $\mu \mathrm{s}, 10-100 \mathrm{~V})$. In current-clamp recording, this stimulation evokes action potentials in mitral cell axons that backpropagate into primary and secondary dendrites, leading to glutamate release from dendrodendritic synapses. In WT mice, LOT stimulation evoked an antidromic action potential followed by a prolonged depolarization (11 of 15 cells; $6.36 \pm 1.89 \mathrm{mV} \cdot \mathrm{s}$; $n=11$ ) (Fig. 6 $A_{1}$, left) (Aroniadou-Anderjaska et al., 1999), presumably reflecting contributions from both the glomerular and external plexiform layers. This depolarization required activity within the population of stimulated cells, because single action potentials evoked by brief current injection (700-1250 pA, 3-5 $\mathrm{ms})$ in the test mitral cell failed to evoke such a response $(0.05 \pm$ $0.04 \mathrm{mV} \cdot \mathrm{s} ; n=11$ ) (Fig. $6 A_{1}$, right). AP-5 reduced the depolarization $(24.0 \pm 8.6 \%$ of control; $n=9)$ (Fig. $6 A_{2}$, left), whereas NBQX, after washout of AP-5, completely blocked the response $(4.6 \pm 3.5 \%$ of control; $n=9)$ (Fig. $6 A_{2}$, right), indicating that NMDA receptor activity requires the coactivation of AMPA receptors.

In $\mathrm{Cx} 36^{-1-}$ mice, LOT stimulation was much less effective in evoking a prolonged depolarization, although small, short duration responses were present in 5 of 13 mitral cells $(0.54 \pm 0.15$ $\mathrm{mV} \cdot \mathrm{s} ; n=5)$. These depolarizations were blocked with AP-5 and NBQX $(7.8 \pm 2.7 \%$ of control integral; $n=4)$ (Fig. $6 B$, left). Similar to WT mitral cells, single action potentials in $\mathrm{Cx} 36^{-1-}$ mitral cells were not sufficient to generate similar depolarizations (Fig. 6B, right). Because there are no direct connections between mitral cells in $\mathrm{Cx} 36^{-1-}$ mice, these small depolarizations reflect glutamate spillover. The reduction in the size of the depolarization in $\mathrm{Cx} 36^{-1-}$ mice compared with WT $(p=0.01)$ suggests that electrical coupling greatly amplifies excitability within the olfactory bulb.

\section{ORN-evoked activity in mitral cell ensembles}

Stimulation of olfactory nerve afferents can produce synchronized oscillations in all mitral cells that project to the same glomerulus, suggesting that mechanisms within the glomerulus enhance and coordinate activity (Carlson et al., 2000; Schoppa et al., 2001). Although electrical coupling plays an essential role in the generation of lateral excitation within the glomerular layer, spillover can contribute to the synchronized activity of mitral cells (Schoppa and Westbrook, 2001). The results presented here indicate that spillover is most apparent after block of glutamate uptake or antidromic activation of ensembles of olfactory bulb neurons. To address whether electrical coupling and spillover 
play distinct or complementary roles, we examined the response of mitral cell pairs to stimulation of the olfactory nerve layer.

In WT mice, bipolar stimulation (100 $\mu \mathrm{s}, 10-100 \mathrm{~V}$ ) of the olfactory nerve layer evoked a complex series of oscillations superimposed on a persistent depolarization (seven of nine mitral cells) (Fig. $7 A_{1}$ ). In paired recordings of mitral cells projecting the same glomerulus, the oscillations were highly correlated $\left(C_{0} \geq 0.75 ; n=6\right.$ ) (Fig. $\left.7 A_{2}, A_{3}\right)$. In contrast, ORN stimulation failed to evoke oscillations in $\mathrm{C} \times 36^{-1-}$ mice $(n=5)$ (Fig. $\left.7 B_{1}\right)$. However, oscillations could be evoked by ORN stimulation during glutamate uptake block (TBOA; 50 $\mu \mathrm{M})\left(\right.$ Fig. $7 B_{1}$ ). As in the WT cell pairs, the TBOA-induced oscillations were highly synchronized $\left(C_{0} \geq 0.75 ; n=4\right)$ (Fig. $\left.7 B_{2}, B_{3}\right)$. These results suggest that the electrical coupling is necessary for the coordinated activity within the glomerular layer, but enhancing glutamate spillover can generate similar activity patterns.

\section{Discussion}

Glutamate neurotransmission was once considered as exclusively point-to-point signaling requiring the close dimensions between sites of release and the postsynaptic receptors. However, transmitter spillover and electrical coupling can coordinate and boost activity within groups of principal cells. Our results indicate that incoming sensory signals to olfactory bulb glomeruli are distributed within a lateral excitatory network, driven by electrical coupling and to a lesser extent glutamate spillover. This functional specialization provides the basis for amplification of odorant-specific sensory input with the glomerular layer.

\section{The significance of glutamate spillover}

Spillover is now well established at central synapses, wherein transmitter can escape the synaptic cleft and activate receptors on neighboring cells. Whether a transmitter activates distant receptors depends on tissue geometry, as well as the kinetics and location of receptors and transporters (Barbour and Häusser, 1997). In the Schaffer collateral-CA1 pathway, spillover preferentially activates synaptic or extrasynaptic NMDA receptors because of their localization and/or high affinity for glutamate and is increased by uptake block (Diamond, 2001; Arnth-Jensen et al., 2002). In contrast, the specialized morphology of some synapses is more conducive to glutamate spillover, such as the calyceal synapses in the brainstem (Otis and Trussell, 1996; Otis et al., 1996) and synapses in cerebellar glomeruli (Silver et al., 1996; Kinney et al., 1997; Overstreet et al., 1999; DiGregorio et al., 2002). At these synapses, closely clustered release sites and a constrained extrasynaptic space promote transmitter accumulation and pooling as well as spillover. Interestingly, these spillovermediated responses also include a component mediated by AMPA receptors.

Mitral cells in the olfactory bulb present a number of complexities in assessing the role of glutamate spillover. Glutamate

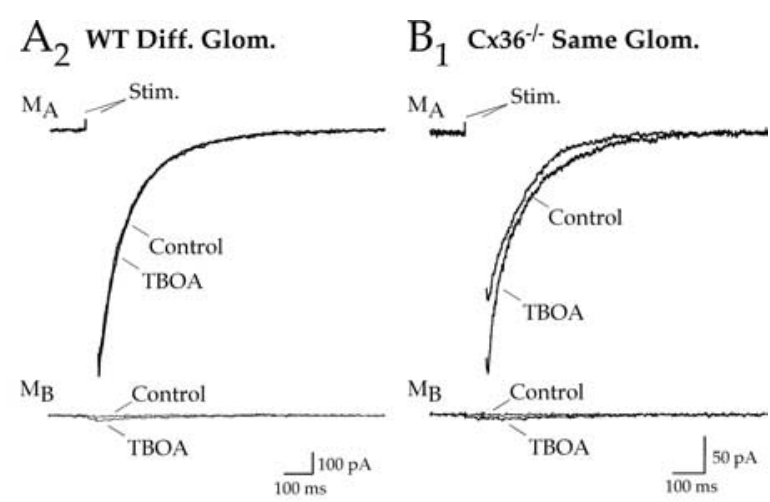

$\mathrm{A}_{3}$ Enlarged

$\mathrm{B}_{2}$ Enlarged
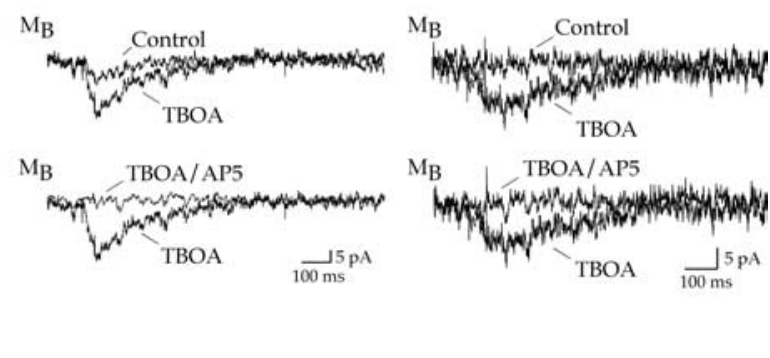

Figure 5. NMDA receptor-mediated spillover currents in secondary dendrites. $\boldsymbol{A}_{1}$, A pair of WT mouse mitral cells, filled with bar, $40 \mu \mathrm{m} . A_{2}, A_{3}$, Top, Stimulation of one mitral cell $\left(\mathrm{M}_{\mathrm{A}}\right)$ in a paired recording evoked barely measurable lateral excitation in lateral excitation was greatly enhanced. TBOA slightly enhanced both WT and $C \times 36^{-1-}$ autoexcitation $(133.5 \pm 9.1 \%$ of control; 11). $\boldsymbol{A}_{3}$, Bottom, Lateral excitation was blocked by AP-5. $\boldsymbol{B}_{1}, \boldsymbol{B}_{2}$, In a CX36 mouse, mitral cell stimulation did not evoke glomeruli and $\mathrm{C}_{3} 6^{-1-}$ mitral cells that projected to the same the glomerulus. TBOA enhanced or uncovered similarly sized currents that were NMDA receptor mediated. Diff., Different; Stim., stimulation; Excit., excitation.

release occurs at primary dendritic tufts within the glomerulus, as well as at dendrodendritic synapses along extensive secondary dendrites (Shepherd and Greer, 1998). Release of glutamate from mitral cells not only excites the postsynaptic receptors on interneurons but also AMPA and NMDA autoreceptors adjacent to the dendritic release site, itself a form of spillover (Nicoll and Jahr, 1982; Isaacson, 1999; Friedman and Strowbridge, 2000; Salin et al., 2001; Schoppa and Westbrook, 2001, 2002). As shown previously and in our experiments, glutamate release also leads to depolarization of neighboring mitral cells, mediated either by NMDA receptors (Isaacson, 1999; Schoppa and Westbrook, 2001) or AMPA and NMDA receptors (Urban and Sakmann, 2002). Because there are no direct synaptic connections between mitral cells (Price and Powell, 1970; Pinching and Powell, 1971), this lateral excitation has been attributed to spillover. However, our results indicate that lateral excitation is not simply spillover, but rather involves electrical coupling between mitral cells within a glomerulus.

\section{Cooperative action of electrical coupling and spillover}

In the rodent, each glomerulus contains the dendritic tufts of 20-25 mitral cells (Shepherd and Greer, 1998). These closely apposed processes are electrically coupled via Cx36-mediated gap junctions (Schoppa and Westbrook, 2002; Christie et al., 2005). Electrical coupling is prominent in the juvenile animals used in our experiments but is also present in adult mice at P42-P44 
$\mathrm{A}_{1} \mathrm{WT}$
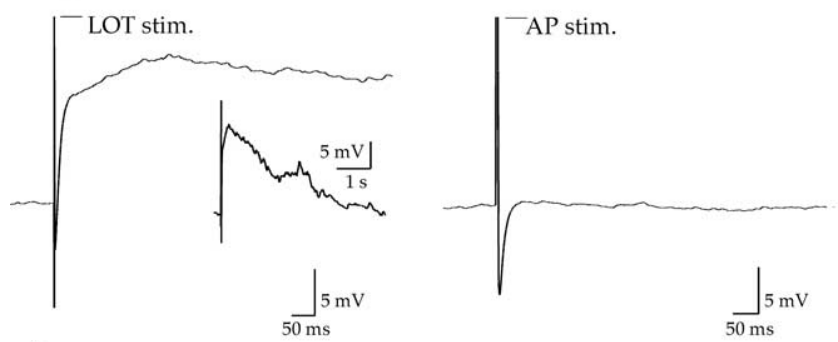

$\mathrm{A}_{2}$
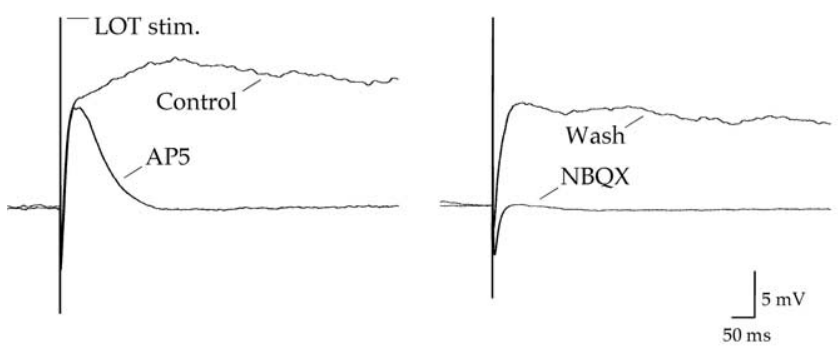

B $\mathrm{C} \times 36^{--}$
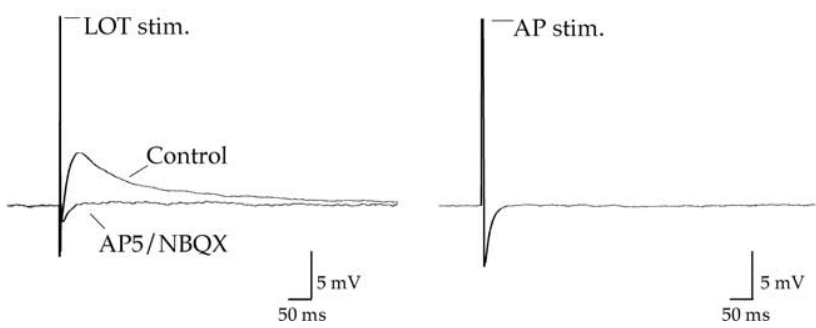

Figure 6. Lateral excitation in $\mathrm{C}_{3} 36^{-1-}$ mice in the absence of uptake block. $\boldsymbol{A}_{\boldsymbol{1}}$, Left, Antidromic stimulation of mitral cell axons via the LOT evoked an action potential followed by a long-lasting depolarization in a mitral cell from a WT mouse; inset, full view. Right, An action potential (AP) elicited by a brief current injection in the same mitral failed to evoke a depolarization. $A_{2}$, The LOT-evoked potential was reduced by AP- 5 and abolished by NBQX. B, Left, LOT stimulation in a mitral cell from a $\mathrm{C} \times 36^{-1-}$ mouse evoked a much smaller afterdepolarization that was sensitive to AP- 5 and NBQX. Right, A single action potential elicited by current injection in the test mitral cell failed to evoke a post-action-potential depolarization. Action potentials have been truncated in all traces. stim., Stimulation; Wash, washout.

(Christie et al., 2005). These previous studies demonstrated that the autoexcitatory depolarization is propagated across gap junctions between mitral cells. Our results indicate that electrical coupling between mitral cells is necessary for lateral excitation, which is also glomerulus specific. In previous studies of $\mathrm{Cx} 36^{-1-}$ mice (Christie et al., 2005), single action potentials in a mitral cell did not depolarize adjacent mitral cells. As reported here, stronger stimulation by action potential trains did not overcome the requirement for electrical coupling in lateral excitation. Lateral excitation evoked by action potential trains depended on the expression of $\mathrm{Cx} 36$-mediated gap junctions and electrical coupling of AMPA and NMDA autoreceptor responses; however, spillover was not apparent. Specifically, there was no evidence of AMPA or NMDA receptor-mediated spillover in physiological concentrations of $\mathrm{Mg}^{2+}$.

Spillover-generated excitation in mitral cell pairs occurred only during glutamate uptake block and between cells that projected their primary dendrites to the same glomerulus. This result implies that transporters tightly regulate spillover between primary dendrites, as observed at more conventional synapses
$\mathrm{A}_{1}$ wT Same Glom.

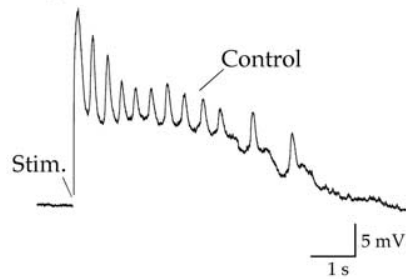

$\mathrm{A}_{2}$ Paired Recording
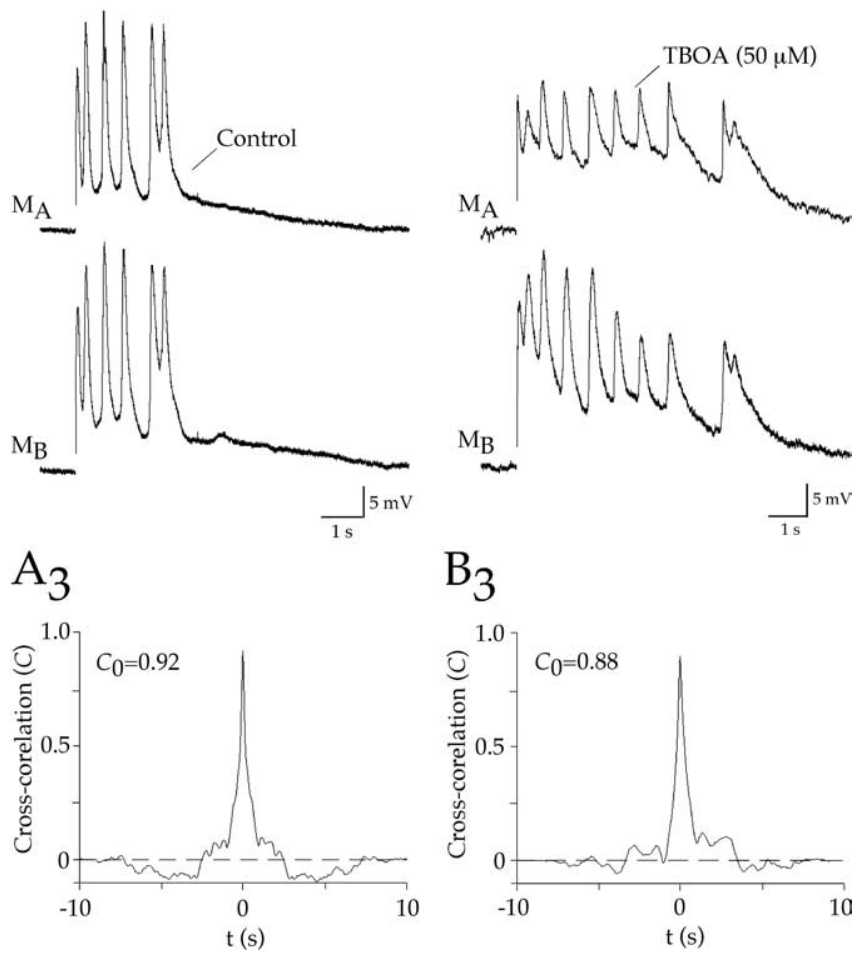

$\mathrm{B}_{3}$

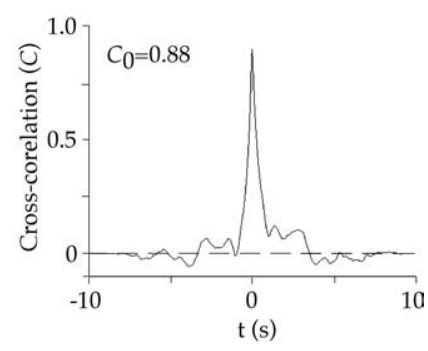

Figure 7. ORN-evoked oscillations in mitral cells are absent in $\mathrm{C}_{3} 36^{-1-}$ mice. $\boldsymbol{A}_{\boldsymbol{1}}$, Orthodromic stimulation of ORN afferents evoked a series of oscillating depolarizations in a WT mitral cell. $A_{2}, A_{3}$, The oscillations were synchronized in mitral cells that projected to the same glomerulus, as indicated by the prominent peak in the cross-correlogram as shown for this example $\left(C_{0}\right.$ is the peak at $\left.\Delta t=0\right) \cdot B_{1}$, In a mitral cell from a $\mathrm{C}_{3} 36^{-1-}$ mouse, $0 \mathrm{RN}$ stimulation failed to evoke oscillating depolarizations. However, oscillations were uncovered after block of glutamate uptake with TBOA. $\boldsymbol{B}_{2}, \boldsymbol{B}_{3}$, The TBOA-induced oscillations were synchronized in mitral cells that projected to the same glomerulus. Stim., Stimulation; Glom., glomerulus.

(Bergles and Jahr, 1998). However, glutamate spillover can also occur during synchronized mitral cell activity, a behavior common to mitral cells that project to the same glomerulus (Carlson et al., 2000; Schoppa and Westbrook, 2001, 2002; Christie et al., 2005). In our experiments, mitral cell excitation elicited by LOT stimulation evoked mitral cell spillover responses in WT and $\mathrm{C} \times 36^{-1-}$ mice. In addition, recordings from periglomerular cells during synchronized mitral cell activity indicate that glutamate accumulation and spillover occur in the glomerulus (Schoppa and Westbrook, 2001). Therefore, the number of mitral cells participating in an ensemble response likely determines whether spillover occurs.

More generally, our observations indicate that electrical coupling and spillover may work cooperatively to promote lateral excitation within groups of mitral cells. Synchronized activity mediated by electrical coupling (Schoppa and Westbrook, 2002; Christie et al., 2005) certainly increases coincident glutamate release from multiple mitral cells, thus enhancing the likelihood of 
spillover-mediated excitation of neighboring dendrites. This may be similar to Schaffer collateral-CA1 pyramidal cell synapses where coincident release also increases spillover-mediated responses (Arnth-Jensen et al., 2002). We suggest that the NMDAreceptor mediated component of lateral excitation in WT mice may also be an example of such cooperation. Because of the reduced excitability of mitral cell ensembles in $\mathrm{Cx} 36^{-1-}$ mice, spillover, and thus NMDA receptor activation, is reduced or eliminated.

\section{Functional segregation of AMPA and NMDA receptor responses}

Intraglomerular mitral cell spillover was mediated by AMPA receptors, as illustrated in Figure $2 B$, a striking result given the relatively low affinity of AMPA receptors for glutamate (Patneau and Mayer, 1990). Autoexcitation in primary dendrites also includes a prominent AMPA receptor component (Salin et al., 2001; Schoppa and Westbrook, 2002). Akin to other specialized synapses (Otis and Trussell, 1996; Otis et al., 1996; Silver et al., 1996; Kinney et al., 1997; Overstreet et al., 1999; DiGregorio et al., 2002), glial-encapsulated dendrodendritic subcompartments (Chao et al., 1997; Kasowski et al., 1999; De Saint Jan and Westbrook, 2005) may allow sufficient pooling of glutamate to activate AMPA receptors (Carlson et al., 2000; Schoppa and Westbrook, 2001). AMPA receptor-mediated spillover responses can also occur at conventional synapses such as the parallel fiberstellate cell synapse, but only with intense presynaptic stimulation (Carter and Regehr, 2000).

Autoexcitation in secondary dendrites of mitral cells is mediated primarily by NMDA receptors (Salin et al., 2001), and NMDA receptors mediate long-lasting depolarizations along secondary dendrites (Aroniadou-Anderjaska et al., 1999; Carlson et al., 2000). As first reported by Isaacson (1999), we could evoke small NMDA receptor-mediated spillover responses with step depolarization of a single mitral cell in the absence of $\mathrm{Mg}^{2+}$. These responses were present in mitral cells projecting to different glomeruli, reflecting spillover between secondary dendrites that are separated by a few micrometers, rather than between glomeruli that are separated by hundreds of micrometers. NMDA receptor-mediated spillover responses could also be evoked after LOT stimulation of a large number of mitral cells; however, this response required the coactivation of AMPA receptors.

These data could suggest a relative segregation of AMPA receptors and NMDA receptors in primary and secondary dendrites, respectively. Whether this represents differences in receptor distribution or simply the conditions of activation in these experiments is far less clear. Immunohistochemical studies indicate that mitral cell secondary dendrites express NMDA receptors, albeit at low density (Sassoe-Pognetto et al., 2003). Although primary dendrites express both NMDA and AMPA receptors (Giustetto et al., 1997; Montague and Greer, 1999), their distribution at ORN-mitral synaptic sites versus other regions of the primary dendritic tuft is not known.

\section{Functional implications}

Gap junctions are well known mediators of rapid oscillations and spike synchrony in neuronal ensembles in neocortex, hippocampus, and inferior olive (Bennett and Zukin, 2004; Connors and Long, 2004). In mitral cells, Cx36-mediated electrical coupling underlies correlated firing in mitral cells that project to the same glomerulus (Schoppa and Westbrook, 2002; Christie et al., 2005). Here, we report that electrical coupling has a more general effect to boost excitability within each glomerulus. Lateral excitatory networks are seemingly rare compared with the widespread existence of lateral inhibition in cortical circuits. Lateral inhibition serves to tune cortical signals in the case in which principal cells excite inhibitory interneurons leading to surround inhibition. However, in some systems, sensory signals are amplified by lateral excitation between cells (DeVries et al., 2002; Herberholz et al., 2002; Antonsen et al., 2005). Gap junctions are a common feature of these lateral excitatory networks. Although our experiments were performed in the presence of a $\mathrm{GABA}_{\mathrm{A}}$ receptor antagonist, inhibition is expected to also shape the overall response to natural stimuli (Schoppa and Urban, 2003).

Because mitral cells projecting to the same glomerulus receive input from afferents expressing the same olfactory receptors, the lateral excitation enabled by electrical coupling can amplify afferent input by spreading excitation to each mitral cell in the ensemble. Entrained mitral cell ensembles may provide temporally coherent network activity thought necessary for processing of olfactory information (Laurent et al., 2001). The interplay of electrical coupling, autoexcitation, and glutamate spillover provides a potent mechanism for glomerulus-specific synchronization of mitral cell activity, the very essence of the idea of glomeruli as functional units (Schoppa and Urban, 2003).

\section{References}

Antonsen BL, Herberholz J, Edwards DH (2005) The retrograde spread of synaptic potentials and recruitment of presynaptic inputs. J Neurosci 25:3086-3094.

Arnth-Jensen N, Jabaudon D, Scanziani M (2002) Cooperation between independent hippocampal synapses is controlled by glutamate uptake. Nat Neurosci 5:325-331.

Aroniadou-Anderjaska V, Ennis M, Shipley MT (1999) Dendrodendritic recurrent excitation in mitral cells of the rat olfactory bulb. J Neurophysiol 82:489-494.

Barbour B, Häusser M (1997) Intersynaptic diffusion of neurotransmitter. Trends Neurosci 20:377-384.

Bennett MV, Zukin RS (2004) Electrical coupling and neuronal synchronization in the mammalian brain. Neuron 41:495-511.

Bergles DE, Jahr CE (1998) Glial contribution to glutamate uptake at Schaffer collateral-commissural synapses in the hippocampus. J Neurosci 18:7709-7716.

Carlson GC, Shipley MT, Keller A (2000) Long-lasting depolarizations in mitral cells of the rat olfactory bulb. J Neurosci 20:2011-2021.

Carter AG, Regehr WG (2000) Prolonged synaptic currents and glutamate spillover at the parallel fiber stellate cell synapse. J Neurosci 20:4423-4434.

Chao TI, Kasa P, Wolff JR (1997) Distribution of astroglia in glomeruli of the rat main olfactory bulb: exclusion from the sensory subcompartment of neuropil. J Comp Neurol 388:191-210.

Christie JM, Bark C, Hormuzdi SG, Helbig I, Monyer H, Westbrook GL (2005) Connexin36 mediates spike synchrony in olfactory bulb glomeruli. Neuron 46:761-772.

Clark BA, Cull-Candy SG (2002) Activity-dependent recruitment of extrasynaptic NMDA receptor activation at an AMPA receptor-only synapse. J Neurosci 22:4428-4436.

Connors BW, Long MA (2004) Electrical synapses in the mammalian brain. Annu Rev Neurosci 27:393-418.

De Saint Jan D, Westbrook GL (2005) Detecting activity in olfactory bulb glomeruli with astrocyte recording. J Neurosci 25:2917-2924.

DeVries SH, Qi X, Smith R, Makous W, Sterling P (2002) Electrical coupling between mammalian cones. Curr Biol 12:1900-1907.

Diamond JS (2001) Neuronal glutamate transporters limit activation of NMDA receptors by neurotransmitter spillover on CA1 pyramidal cells. J Neurosci 21:8328-8338.

DiGregorio DA, Nusser Z, Silver RA (2002) Spillover of glutamate onto synaptic AMPA receptors enhances fast transmission at a cerebellar synapse. Neuron 35:521-533.

Engert F, Bonhoeffer T (1997) Synapse specificity of long-term potentiation breaks down at short distances. Nature 388:279-284. 
Friedman D, Strowbridge BW (2000) Functional role of NMDA autoreceptors in olfactory bulb mitral cells. J Neurophysiol 84:39-50.

Fuxe K, Agnati L (1991) Volume transmission in the brain: new aspects for electrical and chemical communications. New York: Raven.

Giustetto M, Bovolin P, Fasolo A, Bonino M, Cantino D, Sassoe-Pognetto M (1997) Glutamate receptors in the olfactory bulb circuitry: heterogeneity and synaptic localization of $N$-methyl-D-aspartate receptor subunit 1 and AMP receptor subunit 1. Neuroscience 76:787-798.

Herberholz J, Antonsen BL, Edwards DH (2002) A lateral excitatory network in the escape circuit of crayfish. J Neurosci 22:9078-9085.

Hormuzdi SG, Pais I, LeBeau FEN, Towers SK, Rozov A, Buhl EH, Whittington MA, Monyer H (2001) Impaired electrical signaling disrupts gamma frequency oscillations in connexin 36-deficient mice. Neuron 31:487-495.

Isaacson JS (1999) Glutamate spillover mediates excitatory transmission in the rat olfactory bulb. Neuron 23:377-384.

Isaacson JS, Strowbridge B (1998) Olfactory reciprocal synapses: dendritic signaling in the CNS. Neuron 20:749-761.

Jahr CE, Nicoll RA (1982) An intracellular analysis of dendrodendritic inhibition in the turtle in vitro olfactory bulb. J Physiol (Lond) 326:213-234.

Jefferys JG (1995) Nonsynaptic modulation of neuronal activity in the brain: electric currents and extracellular ions. Physiol Rev 75:689-723.

Kasowski HJ, Kim H, Greer CA (1999) Compartmental organization of the olfactory bulb glomerulus. J Comp Neurol 407:261-274.

Kinney GA, Overstreet LS, Slater NT (1997) Prolonged physiological entrapment of glutamate in the synaptic cleft of cerebellar unipolar brush cells. J Neurophysiol 78:1320-1333.

Kullmann DM (2000) Spillover and synaptic cross talk mediated by glutamate and GABA in the mammalian brain. Prog Brain Res 125:339-351.

Laurent G, Stopfer M, Friedrich RW, Rabinovich MI, Volkovskii A, Abarbanel HDI (2001) Odor encoding as an active, dynamical process: experiments, computation, and theory. Annu Rev Neurosci 24:263-297.

Mombaerts P, Wang F, Dulac C, Chao SK, Nemes A, Mendelsohn M, Edmondson J, Axel R (1996) Visualizing an olfactory map. Cell $87: 675-686$.

Montague AA, Greer CA (1999) Differential distribution of ionotropic glutamate receptor subunits in the rat olfactory bulb. J Comp Neurol 405:233-246.

Nicoll RA, Jahr CE (1982) Self-excitation of olfactory bulb neurons. Nature 296:441-444.

Otis TS, Trussell LO (1996) Inhibition of transmitter release shortens the duration of the excitatory synaptic current at a calyceal synapse. J Neurophysiol 76:3584-3588.
Otis TS, Wu YC, Trussell LO (1996) Delayed clearance of transmitter and the role of glutamate transporters at synapses with multiple release sites. J Neurosci 16:1634-1644.

Overstreet LS, Kinney GA, Liu Y, Bilups D, Slater NT (1999) Glutamate transporters contribute to the time course of synaptic transmission in cerebellar granule cells. J Neurosci 19:9663-9673.

Patneau DK, Mayer ML (1990) Structure-activity relationships for amino acid transmitter candidates acting at $N$-methyl-D-aspartate and quisqualate receptors. J Neurosci 10:2385-2399.

Pinching J, Powell TPS (1971) The neuropil of the glomeruli of the olfactory bulb. J Cell Sci 9:347-377.

Price JL, Powell TPS (1970) The mitral cell and short axon cells of the olfactory bulb. J Cell Sci 7:631-651.

Salin PA, Lledo PM, Vincent JD, Charpak S (2001) Dendritic glutamate autoreceptors modulate signal processing in rat mitral cells. J Neurophysiol 85:1275-1282.

Sassoe-Pognetto M, Utvik JK, Camoletto P, Watanabe M, Stephenson FA, Bredt DS, Otterson OP (2003) Organization of postsynaptic density proteins and glutamate receptors in axodendritic and dendrodendritic synapses of the rat olfactory bulb. J Comp Neurol 463:237-248.

Scanziani M (2000) GABA spillover activates postsynaptic $\mathrm{GABA}_{B}$ receptors to control rhythmic hippocampal activity. Neuron 25:673-681.

Scanziani M, Salin PA, Vogt KE, Malenka RC, Nicoll RA (1997) Usedependent increases in glutamate concentration activates presynaptic metabotropic glutamate receptors. Nature 385:630-634.

Schoppa NE, Urban NN (2003) Dendritic processing within olfactory bulb circuits. Trends Neurosci 26:501-506.

Schoppa NE, Westbrook GL (2001) Glomerulus-specific synchronization of mitral cells in the olfactory bulb. Neuron 31:639-651.

Schoppa NE, Westbrook GL (2002) AMPA autoreceptors drive correlated spiking in olfactory bulb glomeruli. Nat Neurosci 5:1194-1202.

Schoppa NE, Kinzie JM, Sahara Y, Segerson TB, Westbrook GL (1998) Dendrodendritic inhibition in the olfactory bulb is driven by NMDA receptors. J Neurosci 18:6790-6802.

Shepherd GL, Greer CA (1998) The synaptic organization of the brain. New York: Oxford UP.

Silver RA, Cull-Candy SG, Takahashi T (1996) Non-NMDA glutamate receptor occupancy and open probability at a rat cerebellar synapse with single and multiple release sites. J Physiol (Lond) 494:231-250.

Urban NN, Sakmann B (2002) Reciprocal intraglomerular excitation and intra- and interglomerular lateral inhibition between mouse olfactory bulb mitral cells. J Physiol (Lond) 542:355-367. 